\title{
A Schedule Optimization Model on Multirunway Based on Ant Colony Algorithm
}

\author{
Yu Jiang, Zhaolong Xu, Xinxing Xu, Zhihua Liao, and Yuxiao Luo \\ College of Civil Aviation, Nanjing University of Aeronautics and Astronautics, Nanjing, Jiangsu 210016, China \\ Correspondence should be addressed to Yu Jiang; jiangyu07@nuaa.edu.cn
}

Received 11 April 2014; Revised 7 July 2014; Accepted 18 July 2014; Published 28 September 2014

Academic Editor: Hu Shao

Copyright (C) $2014 \mathrm{Yu}$ Jiang et al. This is an open access article distributed under the Creative Commons Attribution License, which permits unrestricted use, distribution, and reproduction in any medium, provided the original work is properly cited.

\begin{abstract}
In order to make full use of the slot of runway, reduce flight delay, and ensure fairness among airlines, a schedule optimization model for arrival-departure flights is established in the paper. The total delay cost and fairness among airlines are two objective functions. The ant colony algorithm is adopted to solve this problem and the result is more efficient and reasonable when compared with FCFS (first come first served) strategy. Optimization results show that the flight delay and fair deviation are decreased by $42.22 \%$ and $38.64 \%$, respectively. Therefore, the optimization model makes great significance in reducing flight delay and improving the fairness among all airlines.
\end{abstract}

\section{Introduction}

With the rapid development of the Chinese civil aviation industry, the number of flights increases sharply and hub airports change their single runway to multirunway. The air traffic control managers put first come first served (FCFS) to use to schedule the arrival-departure flights, which can lead to the waste of air resources and make the terminal area congestion more serious. Therefore, the conflict between demand and supply is more and more sharp Hu and Paolo [1]. Meanwhile, with the implementation of collaborative decision making $(\mathrm{CDM})$ mechanism in airport resources management, flight scheduling problem should account for not only flight delay but also equity among airlines. A more efficient and reasonable model or algorithm is needed to approach the problem. Therefore, the air traffic congestion will be alleviated and the total operation cost of airlines will be reduced by approaching the scheduling and optimization of arrival-departure flights.

In recent years, the capacity of most airports cannot satisfy the rapid increase demand because of the increase in number of flights and severe weather. At present, ground delay procedure (GDP) is the main method to be used to approach the contradiction between capacity supply and demand [2]. With the improvement of airport resource management technique, a modified GDP strategy, collaborative ground delay program (CDM-GDP) has been implemented in some hub airports. The modified program can improve the utilization efficiency of airport resources observably [3]. The basic process of CDM-GD is that the air traffic control departments allocate landing slots to airlines; then the airlines can merge and cancel the flights according to the allocated information of slots and feed the adjustment information back to the air traffic control management, and then the air traffic control departments make the final decision after receiving the feedback information from airlines [4]. Many scholars at home and abroad have done some research in CDM-GDP. Hoffman et al. [5] discussed several tools applied to CDM system and a new algorithm ration-byschedule (RBS) was proposed. Vossen et al. [6] described a new allocation procedure based on FCFS in CDM strategy to schedule the arrival-departure flights. They established a equity allocation mechanism, but the efficiency of algorithm should be improved. Mukherjee and Hansen [7] put forward a dynamic stochastic integer programming (IP) model for the airport ground holding problem, but the equity was ignored for small airlines. Ball et al. [8] presented a new ration-by-distance (RBD) algorithm showing that the equity and efficiency were improved at a certain extent. $\mathrm{Hu}$ and $\mathrm{Su}$ [9] modeled the ground-holding management system, which 
provides the theoretical basis and method for the actual traffic management, but they ignored the influence of limited capacity for taking off flights. Ma et al. [10] designed a scheme of approaching queue and optimization schedule of flights. But the satisfaction function is just a local optimization and it is too complicated to make an adjustment in the simulation. Zhou et al. [11] proposed an effectiveness-fairness (E-E) standard aimed at arrival slot time allocated method by analyzing and simulating the traffic flow model in CDMGDP. The simulation results showed that the single priority decreased the total delay cost more efficiently than the double priority and the fair factors were also taken into account. Zhou et al. [12] proposed an evaluation function which was used to evaluate the priority of delay cost coefficient on the basis of existing slot allocation algorithm. The method used in this paper was more flexible and effective compared with the traditional method on the total delay cost and equity, but it lacked the flexibility in slot time allocation for arrival flights. Zhang and $\mathrm{Hu}$ [13] proposed a multiobjective optimization model based on the principles of effectiveness-efficiencyequity trade-offs. But the research lacked further research into the slot time reassignment in CDM GDP based on the real information of aircraft. Zhan et al. [14] adopted the Ant Colony Algorithm (ACA) and receding horizon control (RHC) to optimize the scheduling from the robustness and effectiveness of the queue model on arrival flights. But the instability of the algorithm should be improved and the real scheduling of multirunway should be taken into account. Andrea D'Ariano et al. [15] studied the problem of flight sorting at congested airports. The research regarded the flight scheduling problem as an extension of workshop scheduling problem, but the optimized results were suboptimal feasible solutions. Helmke et al. [16] presented an integrated approach to solve mixed-mode runway scheduling problem by using mixed-integer program techniques. However, further researches into the flight scheduling problem under multirunway with mixed operation were required. Samà et al. [17] presented the real-time scheduling flight in order to reschedule the flight based on receding horizon control strategy and conflict detection. However, the optimization approaches requiring frequent retiming and rerouting in consecutive time horizons decreased the scheduling robustness. Hancerliogullari et al. [18] researched into the aircraft sequencing problem (ASP) under multirunway with mixed operation mode. They put greedy algorithm to simulate the model. However, the fairness among airlines was not taken into consideration.

All in all, though the optimization results of most researches at home and abroad satisfied the scheduling of flight, the studies pay little attention to real-time flight information. Most of the studies consider collaborative ground delays program of approach flight without analyzing departure flight. In fact, if the delay of departure flight is dealt with unreasonably, it can lead to unfairness among arrivaldeparture flights and the increase of flight delay. In the paper, a multiobjective optimization model is established based on multirunway arrival-departure flight. The maximum delay of departure flight is limited to ensure the fairness between arrival-departure flights according to real-time flight information. Meanwhile, a fair runway slot allocation mechanism is established with the objective of minimizing the cost caused by airline delays. As Ant Colony Algorithm has unique advantages in continuous dynamic optimization, the paper introduces it to simulate and validate the model with the expectation of reducing the loss of airline delays, improving runway utilization, and ensuring the fairness among airlines.

\section{Model}

2.1. Description. The queue of arrival-departure flights in multirunway airport is a continuous dynamic process, and it changes with the real-time information of flights. The schedule optimization of arrival-departure flight in multirunway airport can be described as follows: within a time window, a number of flights belonging to different airlines are waiting for landing or taking off. The managers in airport should make a reasonable allocation schedule (such as arrival-departure time, sequence, and operation runway) for all flights to minimize the total delay cost in the study period under the condition of safe operation of flight and airport resources and to balance the cost of total delay among airlines. The paper selects the research time period in rush hour in hub airport to study the airport surface operation. After modeling and simulation, the results can be applied in the management of airport surface operation in any type of airports.

\subsection{Assumptions}

(1) The parallel runways studied in the paper operate independently.

(2) In the research time period, the runway capacity cannot meet the demands of flights.

(3) All the arrival flights do not delay when they are in the take-off airport, and they can arrive at the destination terminal aerospace studied on time.

(4) The basic information (such as flight plans and other information of all flights) within the studied period is known.

(5) Each arrival-departure flight can only be assigned to one time slot in the studied period.

\subsection{Definition}

$$
\begin{aligned}
& F^{A} \text { : Set of arrival flight, } F^{A}=\left\{f_{1}^{A}, f_{2}^{A}, \ldots, f_{m}^{A}\right\} \\
& F^{D}: \text { Set of departure flight, } F^{D}=\left\{f_{1}^{D}, f_{2}^{D}, \ldots, f_{n}^{D}\right\} \\
& F \text { : Set of arrival-departure flights, } F^{A} \cup F^{D}=F \\
& H: \text { Set of airlines, } H=\left\{H_{1}, H_{2}, \ldots, H_{p}\right\} \\
& S \text { : Set of arrival-departure flights slots, } S=\left\{s_{1}, s_{2}, \ldots,\right. \\
& \left.s_{W}\right\} \\
& R: \text { Set of runways in the airport, } R=\{1,2, \ldots, r\} \\
& f_{r t i}=\left\{\begin{array}{l}
1 \text { if flight } i \text { takes off or lands on runway } r \\
0 \text { else }
\end{array}\right. \\
& f_{H_{a}}^{i}: \text { Flight } i \text { belongs to airline } H_{a}
\end{aligned}
$$


$s_{g}^{f_{H_{a}}^{A i}}=\left\{\begin{array}{l}1 \text { if flight slot } s_{g} \text { is assigned to an arrival flight } f_{H_{a}}^{A i} \\ 0 \text { else }\end{array}\right.$

$s_{h}^{f_{H_{a}}^{D i}}=\left\{\begin{array}{l}1 \text { if } s_{h} \text { is assigned to adeparture flight } f_{H_{a}}^{D i} \\ 0 \text { else }\end{array}\right.$

$C$ : Total flight delay cost

$C_{H_{a}}$ : Total flight delay cost of airline $H_{a}$

$P C$ : The sum of absolute deviation of flight delay cost

$\alpha_{r}=\left\{\begin{array}{l}1 \text { if any flight lands on runway } r \\ 0 \text { else }\end{array}\right.$

$\beta_{r}= \begin{cases}1 & \text { if any flight takes off on runway } r \\ 0 & \text { else }\end{cases}$

$O R T_{r f_{b}}$ : The end time of flight $f_{b}$ taking off from or landing on runway $r$ after optimization

$S T f_{r f_{c}}$ : The original time of flight $f_{c}$ taking off from or landing on at runway $r$ after optimization

$S_{r b c}^{A}$ : The minimum safety interval of continuous landing on runway $r$

$S_{r b c}^{D}$ : The minimum safety interval of continuous taking off on runway $r$

$S_{r b c}^{A D}$ : The minimum time interval when a departure flight follows an arrival flight on runway $r$

$S_{r b c}^{D A}$ : The minimum time interval when an arrival flight follows a departure flight on runway $r$

$T J T Y_{\max }$ : The maximum delay time when an arrival flight lands in advance compared to scheduled time

TJZY $Y_{\max }$ : The maximum delay time when an arrival flight lands later than the scheduled time

$T L T Y_{\max }$ : The maximum delay time when a departure flight takes off in advance compared to the scheduled time

$T L Z Y_{\max }$ : The maximum delay time when a departure flight takes off later than the scheduled time

$E T f_{H_{a}}^{A i}$ : The estimated arrival time of flight $f_{i}^{A}$ which belongs to $H_{a}$

$E T f_{H_{a}}^{D j}$ : The estimated departure time of flight $f_{j}^{D}$ which belongs to $H_{a}$

$S T f_{H_{a}}^{A i}$ : The actual arrival time of flight $f_{i}^{A}$ belonging to $H_{a}$ after optimization schedule

$S T f_{H_{a}}^{D j}$ : The actual departure time of flight $f_{j}^{D}$ belonging to $H_{a}$ after optimization schedule

$C_{H_{a}}^{A i}$ : The unit time delay cost of arrival flight $f_{i}^{A}$ belonging to $H_{a}$ after optimization schedule

$C_{H_{a}}^{D j}$ : The unit time delay cost of departure flight $f_{j}^{D}$ belonging to $H_{a}$ after optimization schedule.

2.4. Objective Function. Two objectives are taken into consideration in the paper: total delay cost and the fairness among airlines. The total delay cost of all flights is used to reduce the light delay and improve the utilization of runway. The fairness is used to balance the equity among all the airlines and to protect the benefit of small airlines. So a multiobjective function based on it is modeled.
2.4.1. The Objective Function of Delay Cost. Different wake vortex separations between different arrival-departure flights are different according to the types of aircraft. Therefore, we can improve the capacity of runway and reduce total delay time by adjusting the arrival-departure order of all flights. ICAO aircraft wake turbulence separation criteria are specified in Table 1.

The optimized target of delay cost in the paper is to minimize the total delay of all arrival-departure flights, which is based on improving the capacity of runway. The objective function of delay cost can be described as follows:

$$
\begin{aligned}
& \min C \\
& =\min \sum_{r=1}^{r} \sum_{i=1}^{m} \sum_{j=1}^{n} \sum_{a=1}^{p}\left[C_{H_{a}}^{A i}\left(S T f_{H_{a}}^{A i}-E T f_{H_{a}}^{A i}\right) \alpha_{r} s_{g}^{f_{H_{a}}^{A i}}\right. \\
& \left.+C_{H_{a}}^{D j}\left(S T f_{H_{a}}^{D j}-E T f_{H_{a}}^{D j}\right) \beta_{r} s_{h}^{f_{H_{a}}^{D i}}\right] .
\end{aligned}
$$

2.4.2. The Objective Function of Fairness. Delay cost is related to the aircraft type. In general, large airlines are preferred to small aircraft types. If the research only takes the delay cost as a single function, it is likely to lead to serious unfairness among airlines, especially to small airlines. Therefore, absolute deviation of delay cost is introduced to ensure the fairness among airlines.

Definition of standard flight: assume some type of flight to be a standard flight and all other flights can be transformed into it according to aircraft type and delay cost. For example, if we take a large aircraft as a standard flight and the number equals 1 , then a light aircraft may be transformed as 0.6 and a heavy aircraft as 1.8. If a standard flight is denoted by $\bar{f}_{B}, \lambda_{H_{a}}^{i}$ is defined as the number of standard flights after transformation from flight $i$; then the relation expression can be demonstrated as follows:

$$
\lambda_{H_{a}}^{i}=\frac{f_{H_{a}}^{i}}{\bar{f}_{B}} .
$$

In order to ensure fairness among airlines, the researchers first transform all flights belonging to different airlines into standard flights. Then the researchers can calculate the average delay cost of standard flight by using the total delay cost of all flights. In the same way, the researcher can get average delay cost of each airline and the total absolute deviation of delay cost. It is obvious that the lower the total absolute deviation is, the more fairness we can balance among airlines. The fairness optimization objective function of airlines is as follows:

$$
\min P C=\sum_{a=1}^{p}\left|\frac{C}{\sum_{a=1}^{p} \sum_{H_{a}} \lambda_{H_{a}}^{i}}-\frac{C_{H_{a}}}{\sum_{H_{a}} \lambda_{H_{a}}^{i}}\right|,
$$

where $C_{H_{a}} / \sum_{H_{a}} \lambda_{H_{a}}^{i}$ is the average delay cost of flights belonging to airline $H_{a} ; C / \sum_{a=1}^{p} \sum_{H_{a}} \lambda_{H_{a}}^{i}$ is the average delay cost of all flights. 
TABLE 1: Aircraft wake turbulence separation criteria of ICAO.

\begin{tabular}{lccccc}
\hline & & \multicolumn{2}{c}{ Trailing } & \multicolumn{2}{c}{ The minimum distance interval/km } \\
Type of flight & The minimum time interval/s & Small & Large \\
\hline Leading & Large & Heavy & & & \\
Slight & 98 & 74 & 74 & 6 & 6 \\
Large & 138 & 74 & 74 & 10 & 6 \\
Heavy & 167 & 114 & 94 & 12 & 10 \\
\hline
\end{tabular}

\subsection{Constraints. Consider}

$$
\sum_{g=1}^{W} s_{g}^{f_{H_{a}}^{A i}}=1
$$

An arrival flight occupies one slot resource and each slot resource can be assigned to a certain arrival flight. Constraint (4) is the constraint of slot resource allocation for arrival flights:

$$
\sum_{h=1}^{W} s_{h}^{f_{H_{a}}^{D i}}=1 .
$$

Similarly, a departure flight occupies one slot resource and each slot resource can be assigned to a certain departure flight. Constraint (5) is the constraint of slot resource allocation for departure flights:

$$
f_{r t i} \leq 1
$$

For the safety of flight operation, each flight can only occupy one runway and only one or none aircraft can occupy the runway at the same time. A constraint of slot resource allocation of runways is expressed as constraint (6):

$$
\begin{gathered}
\sum f_{r t i} \leq r \\
\alpha_{r}+\beta_{r} \leq 1 \quad \alpha_{r} \in\{0,1\} \quad \beta_{r} \in\{0,1\} .
\end{gathered}
$$

According to constraint (6), at a certain time, the number of flights occupying runways will not be greater than the number of runways. Meanwhile, in order to ensure safety in a certain slot, only one flight is arriving or leaving at runway $r$. The runway resource controlling constraint is shown as constraint (7):

$$
T J T Y_{\max } \leq S T f_{H_{a} D j}-E T f_{H_{a} D j} \leq T J Z Y_{\text {max }}
$$

To ensure the safety of arrival flights, the actual arrival time should meet the maximum delay time (TLTY $Y_{\max }$ and $T L Z Y_{\max }$ ) after optimization. Constraint (8) is to ensure the time of arrival flight:

$$
T J T Y_{\max } \leq S T f_{H_{a} D j}-E T f_{H_{a} D j} \leq T J Z Y_{\max } .
$$

Constraint (9) is to ensure the time of departure flight. Extending the departure flight delay can decrease the service level in most airports and it is necessary to limit the amount of delay time. Like the constraint for arrival flights, the actual departure time should meet the maximum delay time $\left(T J T Y_{\max }\right.$ and $T J Z Y_{\max }$ ) after optimization. Consider

$$
O R T_{r f_{b}}-S T f_{r f_{c}} \geq \begin{cases}S_{r b c}^{A} & \text { continue arrivals } \\ S_{r b c}^{D} & \text { continue departures } \\ S_{r b c}^{A D} & \text { departure follows arrival } \\ S_{r b c}^{D A} & \text { arrival follows departure. }\end{cases}
$$

The minimum safety interval in different conditions which is related to the order of arrival-departure flight should be taken into account. Constraint (10) is the minimum flight safety interval constraint of runway $r$.

\section{Ant Colony Algorithm Design}

Ant Colony Algorithm (ACA) is a metaheuristic algorithm, which uses a heuristic method to search for the space that may be related to feasible solutions. In ACA, the ant can select the path comprehensively based on pheromones and heuristic factors of the environment. It can release the pheromones after traveling the path of the network. In the algorithm, an individual ant can identify and release all the pheromones. All pheromones from the ant colony are used to complete the whole and complex optimization process. ACA has the characteristics of self-organization and distributed computing. Therefore it is able to make a global search. It can effectively avoid local solutions to an extent. Meanwhile, ACA can get the optimized solution faster than other traditional algorithms.

\subsection{Algorithm Description}

3.1.1. Single Runway Flight Scheduling of ACA. Single runway scheduling problem can be transformed to a TSP which takes each flight as a node and the interval time between flights as the path length of nodes. The problem can be solved by traditional ACA, and the results are satisfactory. The model is built as follows: the node $f_{i}$ in the network is the element of flight set $F$ and the distance $f_{i j}$ between nodes $f_{i}$ and $f_{j}$ is the time interval. When the algorithm begins, the ant $k$ heads from a virtual starting node $f_{0}$. The starting node is set up to ensure that all the ants in ACA can start at the same node. The ant $k$ traverses all the nodes of network, so a flight sequence is obtained. We can calculate wait time and delay cost in the queue according to the sequence. The ACA for single runway flight scheduling is shown in Figure 1. 


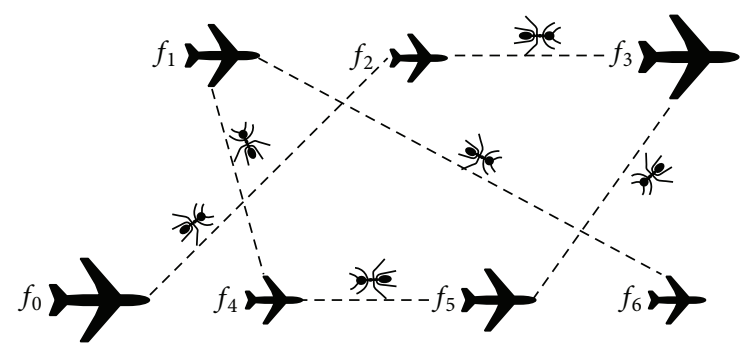

FIgURE 1: The ACA for single runway schedule model.

3.1.2. Multirunway Flight Scheduling of ACA. In order to adapt to the multirunway flight scheduling model, the ACA for single runway model should be modified. In the multirunway flight scheduling model, a node $f_{i}$ may contain several subnodes $r_{n} \in R$. The distance $l_{i_{m} j_{n}}$ between the subnode $r_{m}$ of $f_{i}$ and the subnode $r_{n}$ of node $f_{j}$ is the minimum safety interval. The ant $k$ heads from a virtual starting node $f_{0}$ and travels all nodes of the network. When the ant arrives at a node $f_{i}$, it selects a subnode $r_{n}$ to get a sequence contained runway number. The ACA for multirunway flight scheduling is shown in Figure 2.

3.1.3. The State Transition Equation. The amount of information on each path and the heuristic information can decide the transition direction of ant $k(k=1,2, \ldots, m)$. It records the traveled nodes by search table $\operatorname{tabu}_{k}(k=1,2, \ldots, m)$. $p_{i_{m} j_{n}}^{k}(t)$ is denoted as the state transition probability of ant $k$ changing direction from the subnode $r_{m}$ to the subnode $r_{n}$ at time $t$. Formula (11) is as follows:

$$
p_{i_{m} j_{n}}^{k}(t)= \begin{cases}\frac{\left[\tau_{i_{m} j_{n}}(t)\right]^{\alpha} *\left[\eta_{j_{n}^{\prime}, j_{n}}(t)\right]^{\beta}}{\sum_{\kappa \in \text { allowed }_{k}}\left(\sum_{n \in R}\left[\tau_{i_{m} \kappa_{n}}(t)\right]^{\alpha} * \sum_{n \in R}\left[\eta_{\kappa_{n}^{\prime}, \kappa_{n}}(t)\right]^{\beta}\right)}, & \text { if } \kappa \in \text { allowed }_{k} \\ 0, & \text { otherwise. }\end{cases}
$$

$\tau_{i_{m} j_{n}}(t)$ is the pheromone concentration on path $l_{i_{m} j_{n}}$ at time $t$. allowed $\mathrm{a}_{k}=\left\{F-\mathrm{tabu}_{k}\right\}$ means that the ant $k$ can choose the node which is the node that never traversed next step. $\alpha$ is the pheromone heuristic factor, which decides how the pheromones have impact on path choosing; $\beta$ is the expected heuristic factor, which decides the degree of attention of visibility when ants make a choice.

$\eta_{j_{n}^{\prime}, j_{n}}(t)$ is an expected factor, which is evaluated as

$$
\eta_{j_{n}^{\prime}, j_{n}}(t)=\frac{1}{r_{j_{n}^{\prime}, j_{n}}}
$$

where $r_{j_{n}^{\prime}, j_{n}}$ is the minimum safety interval of the flight $f_{j}$ and former flight $f_{j}^{\prime}$.

3.1.4. The Updating Strategy of Pheromone. Updating pheromone of all nodes is needed when all the iterations are completed. With the increasing of pheromone concentration, the residual pheromone evaporates in proportion. In order to get better optimization results, only the best ant can release pheromone of iteration. Therefore, the pheromone updating can be adjusted as the following rules:

$$
\begin{aligned}
& \tau_{i_{m} j_{n}}(t+1)=\rho \tau_{i_{m} j_{n}}(t)+\Delta \tau_{i_{m} j_{n}}^{\text {best }}, \\
& \Delta \tau_{i_{m} j_{n}}= \begin{cases}\frac{Q}{f\left(k^{\text {best }}\right)}, & i \in k^{\text {best }} \\
0, & i \notin k^{\text {best }},\end{cases}
\end{aligned}
$$

where $\rho$ is the volatilization coefficient of pheromone; $Q$ is the amount of pheromone; $\Delta \tau_{i}$ is the total incremental of pheromone in this circulation of node $i$.
3.2. The Design of ACA. The design of ACA in the simulation is as follows.

Step 1. Set parameters. We set $\alpha=2, \beta=1.5, \rho=0.7$, and $Q=120000$.

Step 2. Get the flight information. We get flight information (including the type of flight, the estimated time of arrival or departure, and so forth) and other known data by reading the files.

Step 3. Initialize the pheromone and expectations of paths of solution space and empty the tabu list.

Step 4. Set $N C=0$ (NC is the iteration). Generate the initial $k$ ants on the virtual node $f_{0}$.

Step 5. Ants select a node orderly according to formula (11).

Step 6. If all ants complete a traversal, turn to Step 7, otherwise turn to Step 5.

Step 7. If the searching results of all ants meet the constraints, then reduce the pheromone increment when updating pheromone.

Step 8. Calculate the target value of all ants and record the best ant solutions.

Step 9. Update the pheromone of each node according to formula (13).

Step 10. If $N C<N C_{\max }$, without stagnating, delete the ant and set $N C \rightarrow N C+1$; then reset the data and turn to Step 5; otherwise output the optimal results and the calculation is over. 


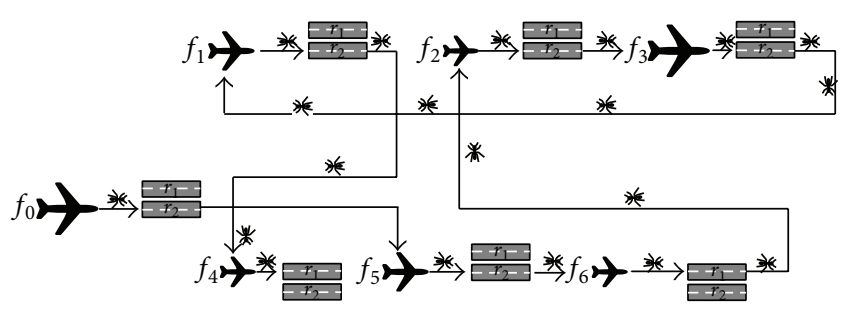

FIGURE 2: The ACA for multirunway schedule model.

\section{Simulation and Vertification}

In the paper, we put $\mathrm{C}$ program to use to simulate flight schedule problem on multirunway with mixed operation mode. The core algorithm of the program is the ACA design. In order to achieve the objectives of delay cost and fairness, we first take the delay cost as the objective and we take fairness as a constraint and we can get the flight sequence with minimal delay cost. After that, we set fairness as the objective and the delay cost as a constraint, and we get a flight sequence with the best fairness. Finally, the initial flight sequence and these two flight sequences are compared. A peak hour is selected from a certain large airport of China and the authors chose flights in the busiest 15 minutes from that peak hour. Two parallel runways run independently. There are 38 flights (belonging to 7 airlines) to be scheduled. After optimization, the initial flight information and optimized results are shown in Table 2.

In the paper, some real operation data is selected from a certain hub airport and ACA is designed to solve the model. As shown in Table 2, flight delay is serious due to unreasonable slot assignment; it can lead to unfair competition among airlines before optimization. The total delay cost of three types of flight sequences is listed in Table 3 and Figure 3.

The initial sequence is the initial flight sequence before optimization. The minimal delay cost and fairness among airlines are solved according to object function (1) and function (2). The minimal delay sequence means that we take the objective function (1) as the main objective function and objective function (2) as a constraint in optimization. The best fairness sequence means that we set objective function (2) as the main objective function and the objective function (1) as a constraint in optimization. Then the paper contrasts the three flight data among airlines.

The detailed information of delay cost of standard flight is listed in Table 4 and Figure 4. After transforming flights into standard flights, we can compare delay cost and fairness directly.

From Figures 3 and 4, we can draw the conclusion that the sequence of minimal delay cost can decrease the delay cost obviously after optimization. The sequence of best fairness can improve the fairness among all the airlines obviously. But from Figure 4, we can see that the fairness among 7 airlines decreases when delay cost is minimal; the delay cost of 7 airlines improves obviously when the fairness is best.

In order to reduce the delay cost of airlines and increase the fairness among airlines, we view the minimum delay

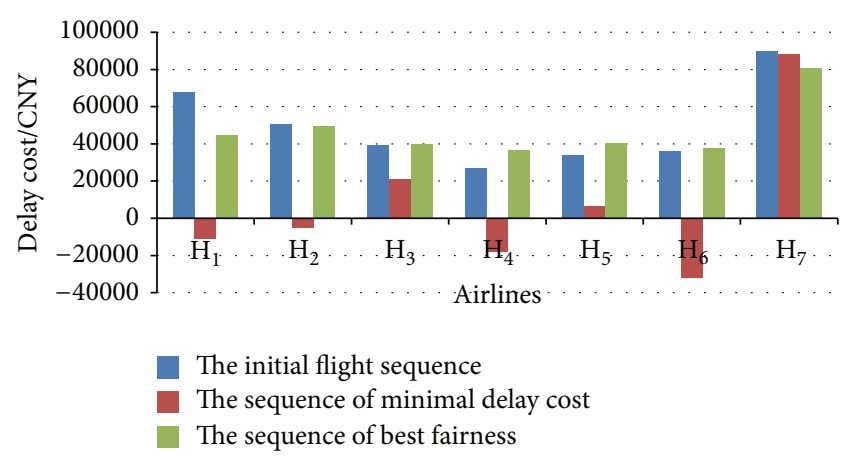

FIgURE 3: The delay cost comparison of airlines on three flight sequences.

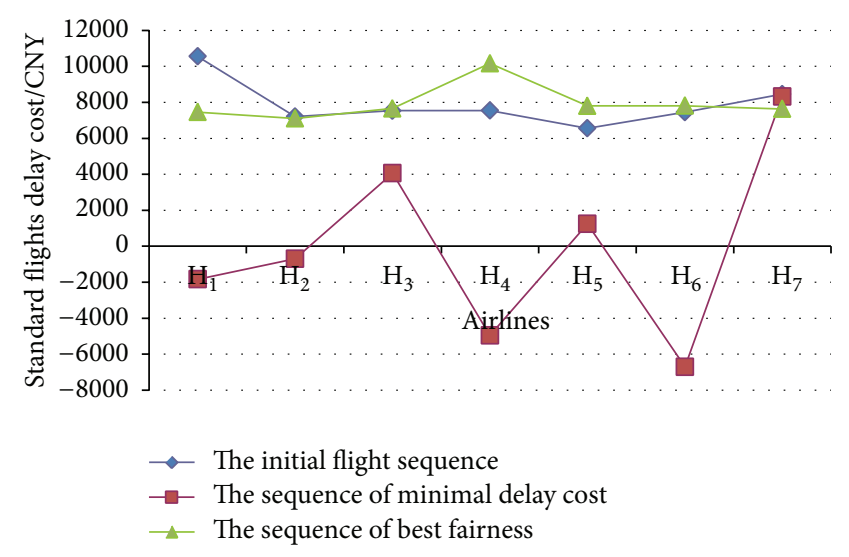

FIgURE 4: The delay cost comparison of airlines standard flights on three flight sequences.

cost as objective and control the range of flight delay cost variation. The simulation steps are as follows.

(1) First, the fairness is not taken into account and we get the minimum delay cost. We statistic the total delay and the delay cost deviation.

(2) Then limit the range of airline flight delay cost deviation by a large number of data. We get the simulated data of total delay and delay cost deviation of flights in the cases $P C<50000, P C<30000, P C<$ 25000, $P C<20000, P C<15000$, respectively.

(3) Finally, we make an analysis of simulation data and study the relationship between the delay cost and fairness. The relation curve of delay cost and delay cost deviation is shown in Figure 5.

As shown in Figure 5, there is a trend relationship between delay cost and fairness. When the delay cost decreases, the fairness among airlines is not satisfied. Reducing the delay deviation of flights may lead to the increase in total delay cost. In order to make balance of the relationship between the delay cost and fairness and make a better 
TABLE 2: The initial flight delay data.

\begin{tabular}{|c|c|c|c|c|c|c|c|}
\hline $\begin{array}{l}\text { Flight } \\
\text { number }\end{array}$ & Airline & Type & $\begin{array}{l}\text { Unit delay cost } \\
\text { of departure }\end{array}$ & $\begin{array}{c}\text { Estimated } \\
\text { time of departure }\end{array}$ & $\begin{array}{c}\text { Actual } \\
\text { time of departure }\end{array}$ & Departure runway & $\begin{array}{l}\text { The delay cost of } \\
\text { actual departure }\end{array}$ \\
\hline F001 & $\mathrm{H}_{1}$ & $\mathrm{~S}$ & 1.2 & 0:00:00 & 0:00:00 & 0 & 0 \\
\hline F002 & $\mathrm{H}_{2}$ & S & 1.1 & 0:00:00 & 0:01:36 & 0 & 105.6 \\
\hline F003 & $\mathrm{H}_{2}$ & $\mathrm{~L}$ & 6.2 & 0:00:00 & 0:02:42 & 0 & 1004.4 \\
\hline F004 & $\mathrm{H}_{3}$ & M & 2.4 & 0:00:00 & 0:00:00 & 1 & 0 \\
\hline F005 & $\mathrm{H}_{4}$ & M & 2.5 & 0:05:00 & $0: 04: 20$ & 0 & -100 \\
\hline F006 & $\mathrm{H}_{4}$ & $\mathrm{~S}$ & 1.4 & 0:05:00 & 0:08:29 & 1 & 292.6 \\
\hline F007 & $\mathrm{H}_{5}$ & M & 2.4 & 0:05:00 & 0:09:35 & 1 & 660 \\
\hline F008 & $\mathrm{H}_{6}$ & M & 2.6 & 0:05:00 & $0: 08: 42$ & 0 & 577.2 \\
\hline F009 & $\mathrm{H}_{6}$ & $\mathrm{~L}$ & 5.7 & 0:10:00 & $0: 17: 41$ & 0 & 2627.7 \\
\hline F010 & $\mathrm{H}_{3}$ & M & 2.4 & 0:10:00 & 0:19:07 & 1 & 1312.8 \\
\hline F011 & $\mathrm{H}_{1}$ & M & 2.3 & 0:10:00 & $0: 20: 23$ & 1 & 1432.9 \\
\hline F012 & $\mathrm{H}_{2}$ & $\mathrm{~L}$ & 6.2 & $0: 10: 00$ & $0: 18: 59$ & 0 & 3341.8 \\
\hline F013 & $\mathrm{H}_{7}$ & M & 2.7 & 0:10:00 & $0: 20: 37$ & 0 & 1719.9 \\
\hline F014 & $\mathrm{H}_{5}$ & S & 1.3 & $0: 15: 00$ & $0: 25: 11$ & 1 & 794.3 \\
\hline F015 & $\mathrm{H}_{2}$ & M & 2.6 & $0: 15: 00$ & $0: 25: 15$ & 0 & 1599 \\
\hline F016 & $\mathrm{H}_{7}$ & M & 2.7 & $0: 15: 00$ & $0: 26: 17$ & 1 & 1827.9 \\
\hline F017 & $\mathrm{H}_{3}$ & $\mathrm{~S}$ & 1 & $0: 15: 00$ & $0: 27: 15$ & 0 & 735 \\
\hline F018 & $\mathrm{H}_{1}$ & $\mathrm{~L}$ & 5.1 & 0:15:00 & $0: 27: 33$ & 1 & 3840.3 \\
\hline $\begin{array}{l}\text { Flight } \\
\text { number }\end{array}$ & Airline & Type & $\begin{array}{l}\text { Unit delay cost } \\
\text { of approach }\end{array}$ & $\begin{array}{c}\text { Estimated } \\
\text { time of approach }\end{array}$ & $\begin{array}{c}\text { Actual } \\
\text { time of approach }\end{array}$ & Approach runway & $\begin{array}{l}\text { The delay cost of } \\
\text { actual approach }\end{array}$ \\
\hline F019 & $\mathrm{H}_{7}$ & $\mathrm{~L}$ & 62.6 & 0:00:00 & 0:01:14 & 1 & 4632.4 \\
\hline F020 & $\mathrm{H}_{7}$ & S & 25.6 & 0:01:12 & 0:04:01 & 1 & 4326.4 \\
\hline F021 & $\mathrm{H}_{7}$ & M & 42.8 & $0: 02: 32$ & 0:05:15 & 1 & 6976.4 \\
\hline F022 & $\mathrm{H}_{5}$ & $\mathrm{~L}$ & 63.2 & 0:03:56 & $0: 04: 16$ & 0 & 1264 \\
\hline F023 & $\mathrm{H}_{4}$ & M & 41.5 & 0:04:02 & $0: 06: 29$ & 1 & 6100.5 \\
\hline F024 & $\mathrm{H}_{6}$ & M & 41.6 & $0: 04: 31$ & 0:06:10 & 0 & 4118.4 \\
\hline F025 & $\mathrm{H}_{7}$ & $\mathrm{~S}$ & 25.6 & 0:05:06 & 0:11:53 & 1 & 10419.2 \\
\hline F026 & $\mathrm{H}_{3}$ & M & 42 & $0: 05: 34$ & 0:09:56 & 0 & 11004 \\
\hline F027 & $\mathrm{H}_{7}$ & M & 42.8 & $0: 05: 42$ & 0:11:10 & 0 & 14038.4 \\
\hline F028 & $\mathrm{H}_{1}$ & M & 42.4 & 0:06:54 & 0:13:07 & 1 & 15815.2 \\
\hline F029 & $\mathrm{H}_{7}$ & $\mathrm{~L}$ & 62.6 & 0:07:01 & $0: 12: 24$ & 0 & 20219.8 \\
\hline F030 & $\mathrm{H}_{7}$ & $\mathrm{~L}$ & 62.6 & $0: 07: 34$ & $0: 14: 21$ & 1 & 25478.2 \\
\hline F031 & $\mathrm{H}_{4}$ & M & 41.5 & 0:08:03 & $0: 16: 15$ & 1 & 20418 \\
\hline F032 & $\mathrm{H}_{3}$ & S & 24.7 & $0: 08: 43$ & $0: 15: 11$ & 0 & 9583.6 \\
\hline F033 & $\mathrm{H}_{5}$ & $\mathrm{~L}$ & 63.2 & 0:09:12 & $0: 17: 29$ & 1 & 31410.4 \\
\hline F034 & $\mathrm{H}_{3}$ & M & 42 & 0:09:51 & $0: 16: 25$ & 0 & 16548 \\
\hline F035 & $\mathrm{H}_{6}$ & M & 41.6 & 0:10:13 & $0: 21: 37$ & 1 & 28454.4 \\
\hline F036 & $\mathrm{H}_{1}$ & M & 42.4 & $0: 10: 14$ & $0: 21: 51$ & 0 & 29552.8 \\
\hline F037 & $\mathrm{H}_{2}$ & $\mathrm{~L}$ & 63 & 0:11:06 & $0: 22: 51$ & 1 & 44415 \\
\hline F038 & $\mathrm{H}_{1}$ & M & 42.4 & 0:12:53 & 0:24:09 & 0 & 16900 \\
\hline
\end{tabular}

TABLE 3: Comparison on delay cost of flights from three flight sequences.

\begin{tabular}{lccccccc}
\hline Airline sequence & $\mathrm{H}_{1}$ & $\mathrm{H}_{2}$ & $\mathrm{H}_{3}$ & $\begin{array}{c}\mathrm{H}_{4} \\
\text { Total delay cost }\end{array}$ & $\mathrm{H}_{5}$ & $\mathrm{H}_{6}$ \\
\hline Initial & & & \multicolumn{3}{c}{$\mathrm{H}_{7}$} \\
Minimal delay & -11009 & -4900.6 & 21132.1 & -17837.5 & 6450.6 & 36070.3 & 89638.6 \\
Best fairness & 44734.4 & 49719.8 & 39821.5 & 36614.3 & 40545.6 & 37500.4 & 88220 \\
\hline
\end{tabular}


TABLE 4: Comparison on delay cost of standard flights from three flight sequences.

\begin{tabular}{|c|c|c|c|c|c|c|c|}
\hline Airline sequence & $\mathrm{H}_{1}$ & $\mathrm{H}_{2}$ & $\mathrm{H}_{3}$ & $\begin{array}{c}\mathrm{H}_{4} \\
\text { Total delay cost }\end{array}$ & $\mathrm{H}_{5}$ & $\mathrm{H}_{6}$ & $\mathrm{H}_{7}$ \\
\hline Initial & 11256.87 & 7209.4 & 7535.27 & 7548.92 & 6563.21 & 7453.69 & 8456.47 \\
\hline Minimal delay & -1834.83 & -700.086 & 4063.865 & -4954.86 & 1240.5 & -6702.21 & 8322.642 \\
\hline Best fairness & 7455.733 & 7102.82 & 7657.981 & 10170.64 & 7797.23 & 7812.583 & 7636.547 \\
\hline
\end{tabular}

Note: $\mathrm{H}_{1}$ to $\mathrm{H}_{7}$ refer to standard flights in Table 4 .

TABLE 5: Comparison on total delay of five flight sequences for flights.

\begin{tabular}{lccccccc}
\hline Airline sequence & $\mathrm{H}_{1}$ & $\mathrm{H}_{2}$ & $\mathrm{H}_{3}$ & $\begin{array}{c}\mathrm{H}_{4} \\
\text { Total delay cost }\end{array}$ & $\mathrm{H}_{5}$ & $\mathrm{H}_{6}$ \\
\hline Minimal delay & -11009 & -4900.6 & 21132.1 & -17837.5 & 6450.6 & -32170.6 & 88220 \\
Optimization 1 & 19309.8 & 5431.1 & 17095 & 5972.5 & 8288.5 & 28083 \\
Optimization 2 & 33832.6 & 48721.1 & 41518.3 & 17449.4 & 19336.1 & 33148.5 & 58219.5 \\
Optimization 3 & 16693.8 & 13682.5 & 20322.1 & 15976.9 & 14430.4 & 6743.8 & 33800.8 \\
Best fairness & 44734.4 & 49719.8 & 39821.5 & 36614.3 & 40545.6 & 37500.4 & 80947.4 \\
\hline
\end{tabular}

TABLE 6: Comparison on delay cost of five flight sequences for standard flights.

\begin{tabular}{lccccccc}
\hline Airline sequence & $\mathrm{H}_{1}$ & $\mathrm{H}_{2}$ & $\mathrm{H}_{3}$ & $\begin{array}{c}\mathrm{H}_{4} \\
\text { Total delay cost }\end{array}$ & $\mathrm{H}_{5}$ & $\mathrm{H}_{6}$ \\
\hline Minimal delay & -1834.83 & -700.086 & 4063.865 & -4954.86 & 1240.5 & -6702.21 \\
Optimization 1 & 3218.3 & 775.8714 & 3287.5 & 1659.028 & 1593.942 & 5850.625 & 5492.642 .406 \\
Optimization 2 & 5638.767 & 6960.157 & 7984.288 & 4847.056 & 3718.481 & 6905.938 & 5056.83 \\
Optimization 3 & 2782.3 & 1954.643 & 3908.096 & 4438.028 & 2775.077 & 1404.958 & 3188.755 \\
Best fairness & 7455.733 & 7102.829 & 7657.981 & 10170.64 & 7797.231 & 7812.583 & 7636.547 \\
\hline
\end{tabular}

Note: $\mathrm{H}_{1}$ to $\mathrm{H}_{7}$ refer to standard flights in Table 6 .

sequence of flights, we can make flight sequence by limiting the delay deviation of flights. So it not only reduces the total delay cost of airlines but also takes care of the fairness among airlines.

From the simulation results, we can get a number of flight sequences by controlling the sum of absolute deviation of flight delay cost. Five sequences (minimal delay cost, optimization 1, optimization 2, optimization 3, and the best fairness) to make a comparison of total delay cost of airlines are shown in Table 5 and Figure 6. Table 6 and Figure 7 show the same comparison by transforming flights into standard flights.

The total delay cost and the fairness among airlines have been improved obviously after optimization. In actual operation, the decision makers can get several optimized flight sequences by controlling the range of flight delay cost deviation and by selecting a preferred one according to realtime information.

In Table 7, we list the optimal flight sequence in which both the delay cost and fairness are acceptable. The optimized results show that the total delay cost reduces greatly and the fairness is also acceptable when compared with the initial flight sequence. The standard flight delay cost deviation of initial flight sequence and optimized flight sequence is

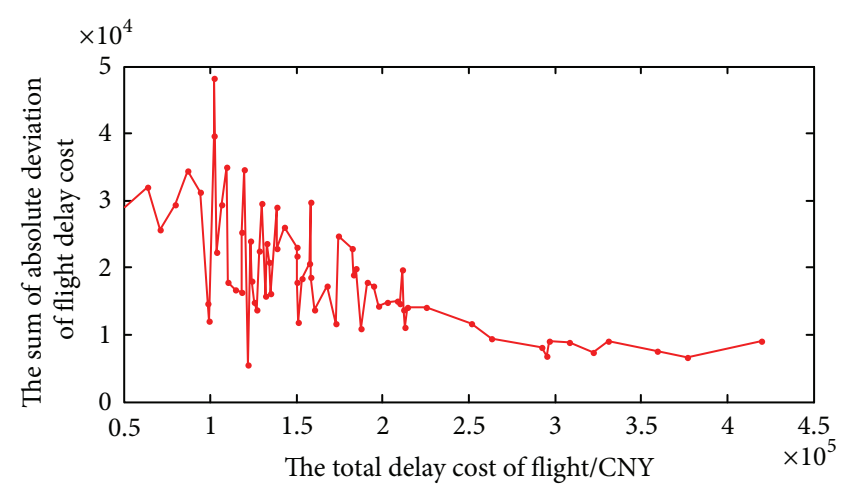

Figure 5: The trend relationship between delay cost and fairness.

calculated based on Table 7. The results are shown in Table 8 and Figure 8. The histogram shows the contrast of flight delay deviation between the initial flight sequence and the optimized flight sequence. From the histogram we can find that the delay cost of airlines declines $42.22 \%$ at least after optimization. The sum of delay deviation declines $38.64 \%$. So the schedule model and solution have not only reduced the total delay cost significantly but also ensured the fairness among all the airlines. 
TABLE 7: The comparison between initial flight delay cost and the optimized flight delay cost.

\begin{tabular}{|c|c|c|c|c|c|c|c|c|c|}
\hline $\begin{array}{l}\text { Flight } \\
\text { number }\end{array}$ & Type & $\begin{array}{l}\text { Unit delay cost } \\
\text { of departure }\end{array}$ & $\begin{array}{c}\text { Estimated } \\
\text { time of } \\
\text { departure }\end{array}$ & $\begin{array}{c}\text { Actual } \\
\text { time of } \\
\text { departure }\end{array}$ & $\begin{array}{l}\text { Departure } \\
\text { runway }\end{array}$ & $\begin{array}{l}\text { Delay cost } \\
\text { of actual } \\
\text { departure }\end{array}$ & $\begin{array}{c}\text { Optimal } \\
\text { Departure } \\
\text { time }\end{array}$ & $\begin{array}{c}\text { Departure } \\
\text { runway after } \\
\text { optimization }\end{array}$ & $\begin{array}{l}\text { Departure delay cost } \\
\text { after optimization }\end{array}$ \\
\hline $\mathrm{H}_{1} \mathrm{~F} 001$ & $S$ & 1.2 & 0:00:00 & 0:00:00 & 0 & 0 & $0: 18: 30$ & 0 & 1332 \\
\hline $\mathrm{H}_{2} \mathrm{~F} 002$ & S & 1.1 & 0:00:00 & 0:01:36 & 0 & 105.6 & 0:08:50 & 1 & 583 \\
\hline $\mathrm{H}_{2} \mathrm{~F} 003$ & $\mathrm{~L}$ & 6.2 & 0:00:00 & $0: 02: 42$ & 0 & 1004.4 & $0: 11: 58$ & 0 & 4451.6 \\
\hline $\mathrm{H}_{3} \mathrm{~F} 004$ & M & 2.4 & 0:00:00 & 0:00:00 & 1 & 0 & 0:03:10 & 0 & 456 \\
\hline $\mathrm{H}_{4} \mathrm{~F} 005$ & M & 2.5 & 0:05:00 & $0: 04: 20$ & 0 & -100 & $0: 14: 54$ & 0 & 1485 \\
\hline $\mathrm{H}_{4} \mathrm{~F} 006$ & S & 1.4 & 0:05:00 & 0:08:29 & 1 & 292.6 & $0: 22: 20$ & 1 & 1456 \\
\hline $\mathrm{H}_{5} \mathrm{~F} 007$ & M & 2.4 & 0:05:00 & 0:09:35 & 1 & 660 & $0: 11: 12$ & 1 & 892.8 \\
\hline $\mathrm{H}_{6} \mathrm{~F} 008$ & M & 2.6 & 0:05:00 & $0: 08: 42$ & 0 & 577.2 & $0: 27: 30$ & 1 & 3510 \\
\hline $\mathrm{H}_{6} \mathrm{~F} 009$ & $\mathrm{~L}$ & 5.7 & 0:10:00 & $0: 17: 41$ & 0 & 2627.7 & $025: 44$ & 0 & 5380.8 \\
\hline $\mathrm{H}_{3} \mathrm{~F} 010$ & M & 2.4 & 0:10:00 & 0:19:07 & 1 & 1312.8 & $0: 26: 16$ & 1 & 2342.4 \\
\hline $\mathrm{H}_{1} \mathrm{~F} 011$ & M & 2.3 & 0:10:00 & $0: 20: 23$ & 1 & 1432.9 & $0: 22: 56$ & 0 & 1784.8 \\
\hline $\mathrm{H}_{2} \mathrm{~F} 012$ & $\mathrm{~L}$ & 6.2 & $0: 10: 00$ & $0: 18: 59$ & 0 & 3341.8 & $0: 24: 10$ & 0 & 5270 \\
\hline $\mathrm{H}_{7} \mathrm{~F} 013$ & M & 2.7 & $0: 10: 00$ & $0: 20: 37$ & 0 & 1719.9 & $0: 16: 50$ & 1 & 1107 \\
\hline $\mathrm{H}_{5} \mathrm{~F} 014$ & S & 1.3 & $0: 15: 00$ & $0: 25: 11$ & 1 & 794.3 & 0:19:08 & 1 & 322.4 \\
\hline $\mathrm{H}_{2} \mathrm{~F} 015$ & M & 2.6 & $0: 15: 00$ & $0: 25: 15$ & 0 & 1599 & $0: 13: 44$ & 1 & -197.6 \\
\hline $\mathrm{H}_{7} \mathrm{~F} 016$ & M & 2.7 & $0: 15: 00$ & $0: 26: 17$ & 1 & 1827.9 & $0: 25: 02$ & 1 & 1625.4 \\
\hline $\mathrm{H}_{3} \mathrm{~F} 017$ & S & 1 & $0: 15: 00$ & $0: 27: 15$ & 0 & 735 & $0: 21: 42$ & 0 & 402 \\
\hline $\mathrm{H}_{1} \mathrm{~F} 018$ & $\mathrm{~L}$ & 5.1 & 0:15:00 & $0: 27: 33$ & 1 & 3840.3 & $0: 10: 24$ & 0 & -1407.6 \\
\hline $\begin{array}{l}\text { Flight } \\
\text { number }\end{array}$ & Type & $\begin{array}{l}\text { Unit delay cost } \\
\text { of approach }\end{array}$ & $\begin{array}{l}\text { Estimated } \\
\text { time of } \\
\text { approach }\end{array}$ & $\begin{array}{c}\text { Actual } \\
\text { time of } \\
\text { approach }\end{array}$ & $\begin{array}{l}\text { Approach } \\
\text { runway }\end{array}$ & $\begin{array}{l}\text { Delay cost } \\
\text { of actual } \\
\text { approach }\end{array}$ & $\begin{array}{c}\text { Optimal } \\
\text { Approach } \\
\text { time }\end{array}$ & $\begin{array}{c}\text { Approach } \\
\text { runway after } \\
\text { optimization }\end{array}$ & $\begin{array}{l}\text { Approach delay cost } \\
\text { after optimization }\end{array}$ \\
\hline $\mathrm{H}_{7} \mathrm{~F} 019$ & $\mathrm{~L}$ & 62.6 & 0:00:00 & 0:01:14 & 1 & 4632.4 & 0:06:00 & 0 & 22536 \\
\hline $\mathrm{H}_{7} \mathrm{~F} 020$ & S & 25.6 & 0:01:12 & 0:04:01 & 1 & 4326.4 & $0: 23: 56$ & 1 & 34918.4 \\
\hline $\mathrm{H}_{7} \mathrm{~F} 021$ & M & 42.8 & $0: 02: 32$ & 0:05:15 & 1 & 6976.4 & $0: 02: 28$ & 1 & -171.2 \\
\hline $\mathrm{H}_{5} \mathrm{~F} 022$ & $\mathrm{~L}$ & 63.2 & $0: 03: 56$ & $0: 04: 16$ & 0 & 1264 & $0: 13: 16$ & 0 & 35392 \\
\hline $\mathrm{H}_{4} \mathrm{~F} 023$ & M & 41.5 & 0:04:02 & $0: 06: 29$ & 1 & 6100.5 & $0: 03: 42$ & 1 & -830 \\
\hline $\mathrm{H}_{6} \mathrm{~F} 024$ & M & 41.6 & $0: 04: 31$ & $0: 06: 10$ & 0 & 4118.4 & 0:06:50 & 1 & 5782.4 \\
\hline $\mathrm{H}_{7} \mathrm{~F} 025$ & S & 25.6 & 0:05:06 & $0: 11: 53$ & 1 & 10419.2 & $0: 15: 44$ & 1 & 16332.8 \\
\hline $\mathrm{H}_{3} \mathrm{~F} 026$ & M & 42 & $0: 05: 34$ & 0:09:56 & 0 & 11004 & $0: 07: 54$ & 0 & 5880 \\
\hline $\mathrm{H}_{7} \mathrm{~F} 027$ & M & 42.8 & $0: 05: 42$ & 0:11:10 & 0 & 14038.4 & 0:00:00 & 1 & -14637.6 \\
\hline $\mathrm{H}_{1} \mathrm{~F} 028$ & M & 42.4 & $0: 06: 54$ & 0:13:07 & 1 & 15815.2 & $0: 12: 28$ & 1 & 14161.6 \\
\hline $\mathrm{H}_{7} \mathrm{~F} 029$ & $\mathrm{~L}$ & 62.6 & 0:07:01 & $0: 12: 24$ & 0 & 20219.8 & 0:00:00 & 0 & -26354.6 \\
\hline $\mathrm{H}_{7} \mathrm{~F} 030$ & $\mathrm{~L}$ & 62.6 & $0: 07: 34$ & $0: 14: 21$ & 1 & 25478.2 & $0: 04: 56$ & 1 & -9890.8 \\
\hline $\mathrm{H}_{4} \mathrm{~F} 031$ & M & 41.5 & 0:08:03 & $0: 16: 15$ & 1 & 20418 & 0:09:56 & 1 & 4689.5 \\
\hline $\mathrm{H}_{3} \mathrm{~F} 032$ & S & 24.7 & $0: 08: 43$ & $0: 15: 11$ & 0 & 9583.6 & $0: 20: 44$ & 1 & 17808.7 \\
\hline $\mathrm{H}_{5} \mathrm{~F} 033$ & $\mathrm{~L}$ & 63.2 & 0:09:12 & $0: 17: 29$ & 1 & 31410.4 & $0: 04: 26$ & 0 & -18075.2 \\
\hline $\mathrm{H}_{3} \mathrm{~F} 034$ & M & 42 & 0:09:51 & $0: 16: 25$ & 0 & 16548 & 0:01:54 & 0 & -20034 \\
\hline $\mathrm{H}_{6} \mathrm{~F} 035$ & M & 41.6 & $0: 10: 13$ & $0: 21: 37$ & 1 & 28454.4 & 0:09:08 & 0 & -2704 \\
\hline $\mathrm{H}_{1} \mathrm{~F} 036$ & M & 42.4 & $0: 10: 14$ & $0: 21: 51$ & 0 & 29552.8 & 0:01:14 & 1 & -22896 \\
\hline $\mathrm{H}_{2} \mathrm{~F} 037$ & $\mathrm{~L}$ & 63 & 0:11:06 & $0: 22: 51$ & 1 & 44415 & 0:16:10 & 0 & 19152 \\
\hline $\mathrm{H}_{1} \mathrm{~F} 038$ & $\mathrm{~S}$ & 25 & $0: 12: 53$ & 0:24:09 & 0 & 16900 & $0: 20: 06$ & 0 & 10825 \\
\hline
\end{tabular}

Total: the total cost of the initial flight sequence delay is $343446.5 / \mathrm{CNY}$; the total cost of optimized flight sequence delay is 102681.0/CNY. 
TABLE 8: The total delay cost and deviation of standard flight.

\begin{tabular}{lcccccccr}
\hline Airline sequence & $\mathrm{H}_{1}$ & $\mathrm{H}_{2}$ & $\mathrm{H}_{3}$ & $\begin{array}{c}\mathrm{H}_{4} \\
\text { Total delay cost }\end{array}$ & $\mathrm{H}_{5}$ & $\mathrm{H}_{6}$ & $\mathrm{H}_{7}$ & Deviation \\
\hline Initial & 11256.9 & 7209.4 & 7535.2 & 7548.92 & 6563.21 & 7453.7 & 8456.5 & 10456.5 \\
Optimized & 2782.3 & 1954.6 & 3908.1 & 4438.0 & 2775.1 & 1405.0 & 3188.8 & 5487.0 \\
\hline
\end{tabular}

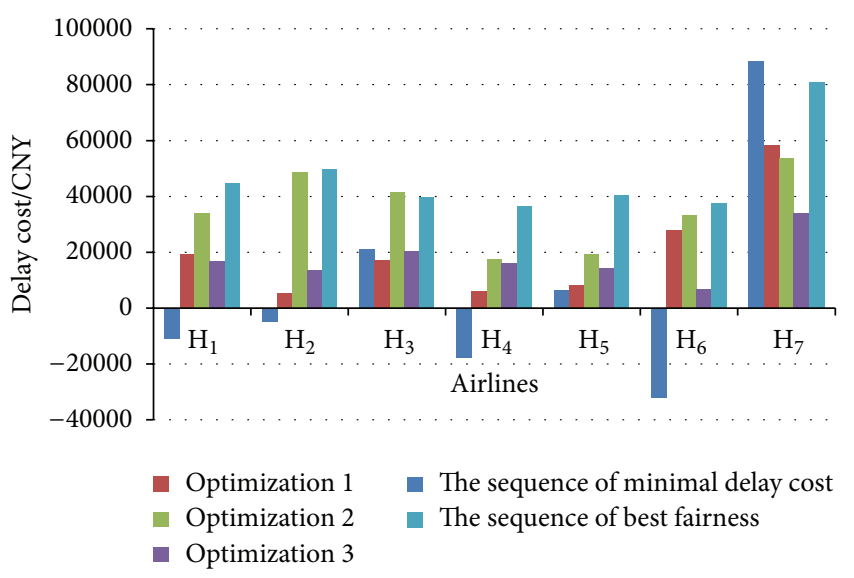

Figure 6: Comparison of the delay cost of airlines.

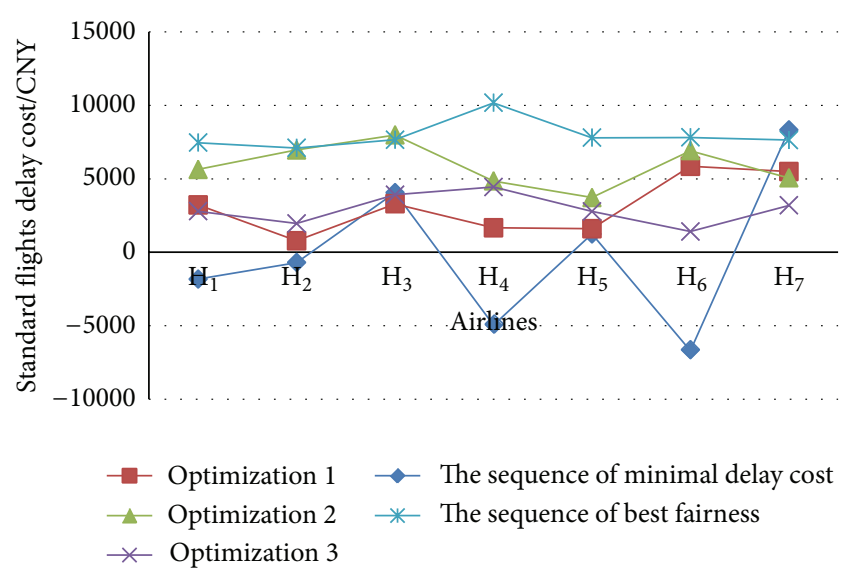

FIGURE 7: Comparison of the delay of five flight sequences for airline standard flights.

\section{Conclusions}

In the paper, a mixed multirunway operation flight scheduling optimization model based on multiobjective is proposed. Two objectives are considered: the total delay cost and fairness among airlines are two objective functions. The ACA is introduced to solve the model. The simulation results show that the total delay cost decreases significantly and the fairness among airlines is also acceptable. Meanwhile, ACA used in the paper solves the model with great efficiency.

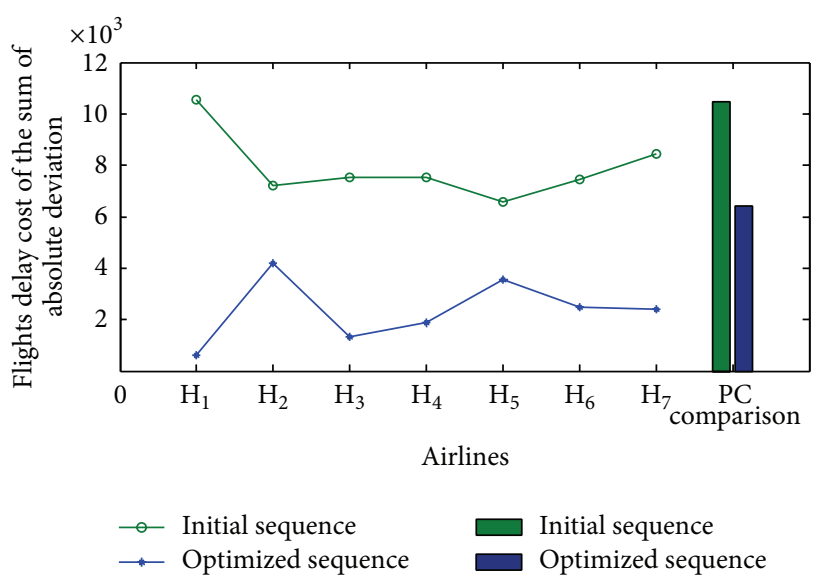

Figure 8: Contrast between the total delay cost and deviation of standard flight.

\section{Conflict of Interests}

The authors declare that there is no conflict of interests regarding the publication of this paper.

\section{Acknowledgments}

This work was supported by the National Natural Science Foundation of China, the Civil Aviation Administration of China (no. U1333117), China Postdoctoral Science Foundation (no. 2012M511275), and the Fundamental Research Funds for the Central Universities (no. NS2013067).

\section{References}

[1] X. Hu and E. di Paolo, "Binary-representation-based genetic algorithm for aircraft arrival sequencing and scheduling," IEEE Transactions on Intelligent Transportation Systems, vol. 9, no. 2, pp. 301-310, 2008.

[2] M. C. Wambsganss, "Collaborative decision making in air traffic management," in New Concepts and Methods in Air Traffic Management, pp. 1-15, Springer, Berlin, Germany, 2001.

[3] M. Wambsganss, "Collaborative decision making through dynamic information transfer," Air Traffic Control Quarterly, vol. 4, no. 2, pp. 107-123, 1997.

[4] K. Chang, K. Howard, R. Oiesen, L. Shisler, M. Tanino, and M. C. Wambsganss, "Enhancements to the FAA ground-delay program under collaborative decision making," Interfaces, vol. 31, no. 1, pp. 57-76, 2001.

[5] R. Hoffman, W. Hall, M. Ball, A. R. Odoni, and M. Wambsganss, "Collaborative decision making in air traffic flow management," NEXTOR Research Report RR-99-2, UC Berkley, 1999. 
[6] T. Vossen, M. Ball, R. Hoffman et al., "A general approach to equity in traffic flow management and its application to mitigating exemption bias in ground delay programs," Air Traffic Control Quarterly, vol. 11, no. 4, pp. 277-292, 2003.

[7] A. Mukherjee and M. Hansen, "A dynamic stochastic model for the single airport ground holding problem," Transportation Science, vol. 41, no. 4, pp. 444-456, 2007.

[8] M. O. Ball, R. Hoffman, and A. Mukherjee, "Ground delay program planning under uncertainty based on the ration-bydistance principle," Transportation Science, vol. 44, no. 1, pp. 1$14,2010$.

[9] M. H. Hu and L. G. Su, "Modeling research in air traffic flow control system," Journal of Nanjing University Aeronautics \& Astronautics, vol. 32, no. 5, pp. 586-590, 2000.

[10] Z. Ma, D. Cui, and C. Chen, "Sequencing and optimal scheduling for approach control of air traffic," Journal of Tsinghua University, vol. 44, no. 1, pp. 122-125, 2004.

[11] Q. Zhou, J. Zhang, and X. J. Zhang, "Equity and effectiveness study of airport flow management model," China Science and Technology Information, vol. 4, pp. 126-116, 2005.

[12] Q. Zhou, X. Zhang, and Z. Liu, "Slots allocation in CDM GDP," Journal of Beijing University of Aeronautics and Astronautics, vol. 32, no. 9, pp. 1043-1045, 2006.

[13] H. H. Zhang and M. H. Hu, "Multi-objection optimization allocation of aircraft landing slot in CDM GDP," Journal of Systems \& Management, vol. 18, no. 3, pp. 302-308, 2009.

[14] Z. Zhan, J. Zhang, Y. Li et al., "An efficient ant colony system based on receding horizon control for the aircraft arrival sequencing and scheduling problem," IEEE Transactions on Intelligent Transportation Systems, vol. 11, no. 2, pp. 399-412, 2010.

[15] A. D'Ariano, P. D'Urgolo, D. Pacciarelli, and M. Pranzo, “Optimal sequencing of aircrafts take-off and landing at a busy airport," in Proceeding of the 13th International IEEE Conference on Intelligent Transportation Systems (ITSC 10), pp. 1569-1574, Funchal, Portugal, September 2010.

[16] H. Helmke, O. Gluchshenko, A. Martin, A. Peter, S. Pokutta, and U. Siebert, "Optimal mixed-mode runway scheduling-mixedinteger programming for ATC scheduling," in Proceedings of the IEEE/AIAA 30th Digital Avionics Systems Conference (DASC '11), pp. C41-C413, IEEE, Seattle, Wash, USA, October 2011.

[17] M. Samà, A. D’Ariano, and D. Pacciarelli, "Optimal aircraft traffic flow management at a terminal control area during disturbances," Procedia-Social and Behavioral Sciences, vol. 54, pp. 460-469, 2012.

[18] G. Hancerliogullari, G. Rabadi, A. H. Al-Salem, and M. Kharbeche, "Greedy algorithms and metaheuristics for a multiple runway combined arrival-departure aircraft sequencing problem," Journal of Air Transport Management, vol. 32, pp. 39-48, 2013. 


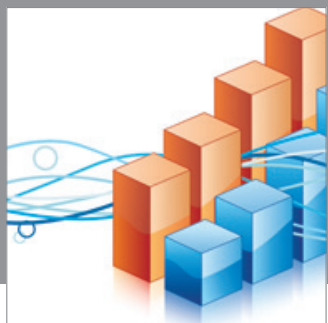

Advances in

Operations Research

mansans

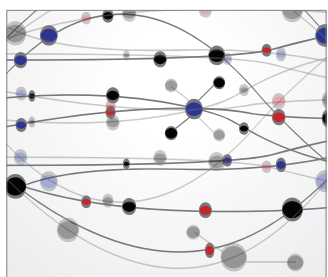

The Scientific World Journal
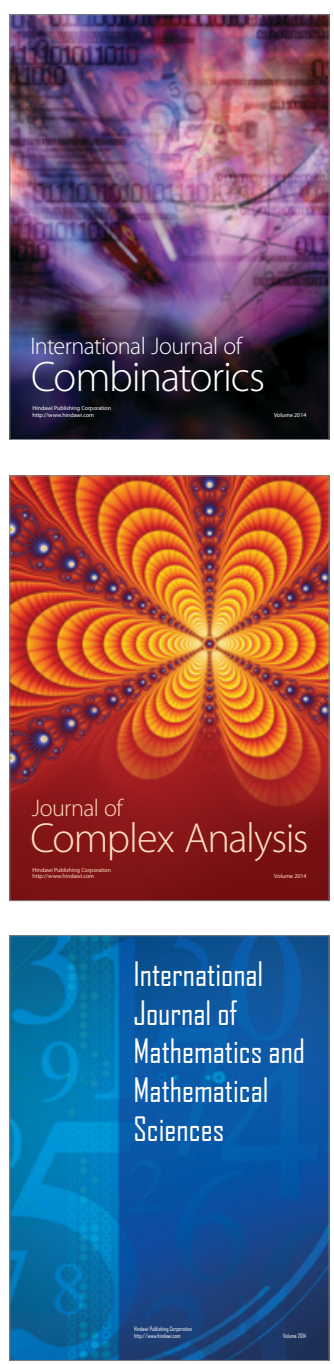
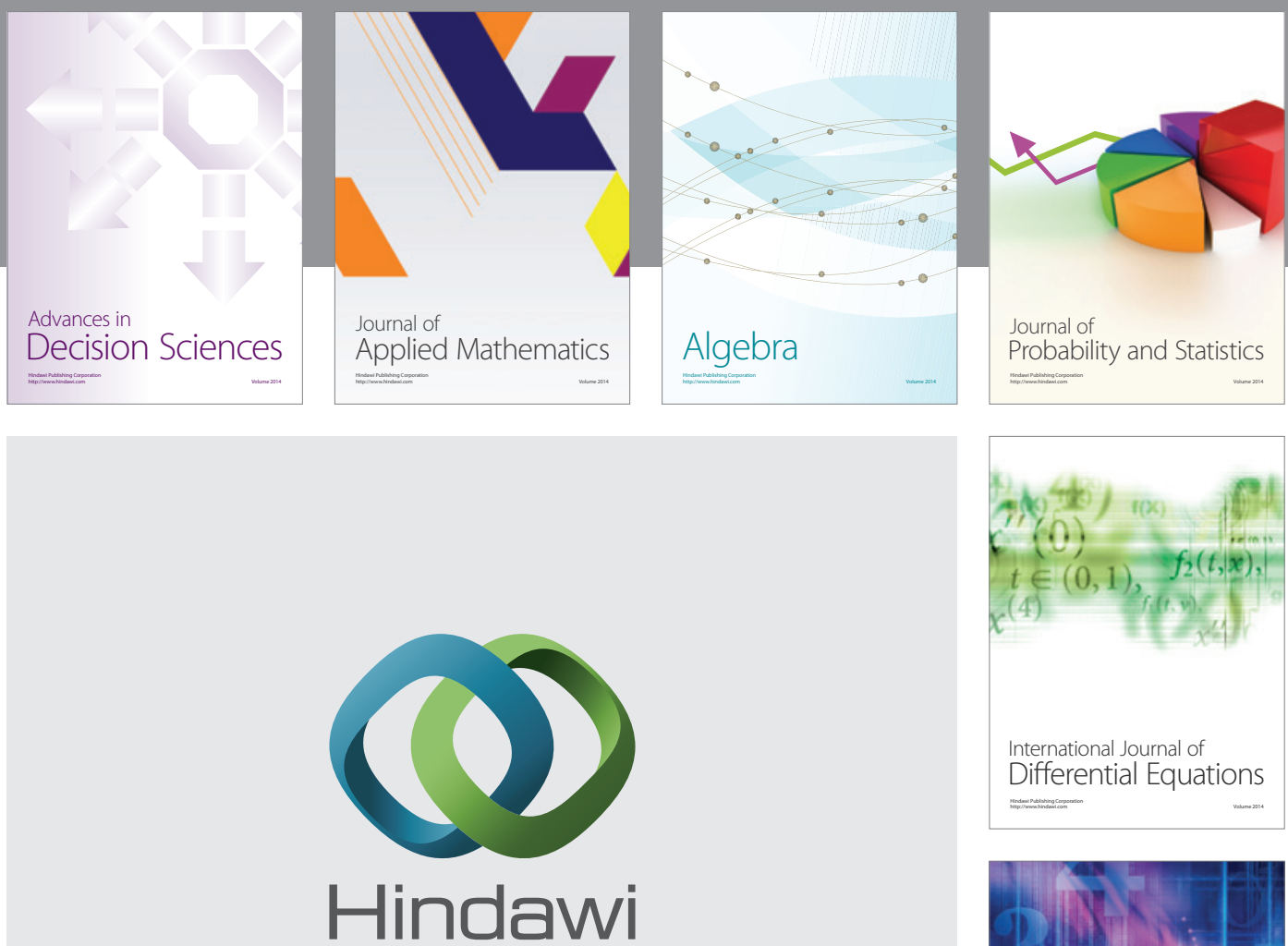

Submit your manuscripts at http://www.hindawi.com
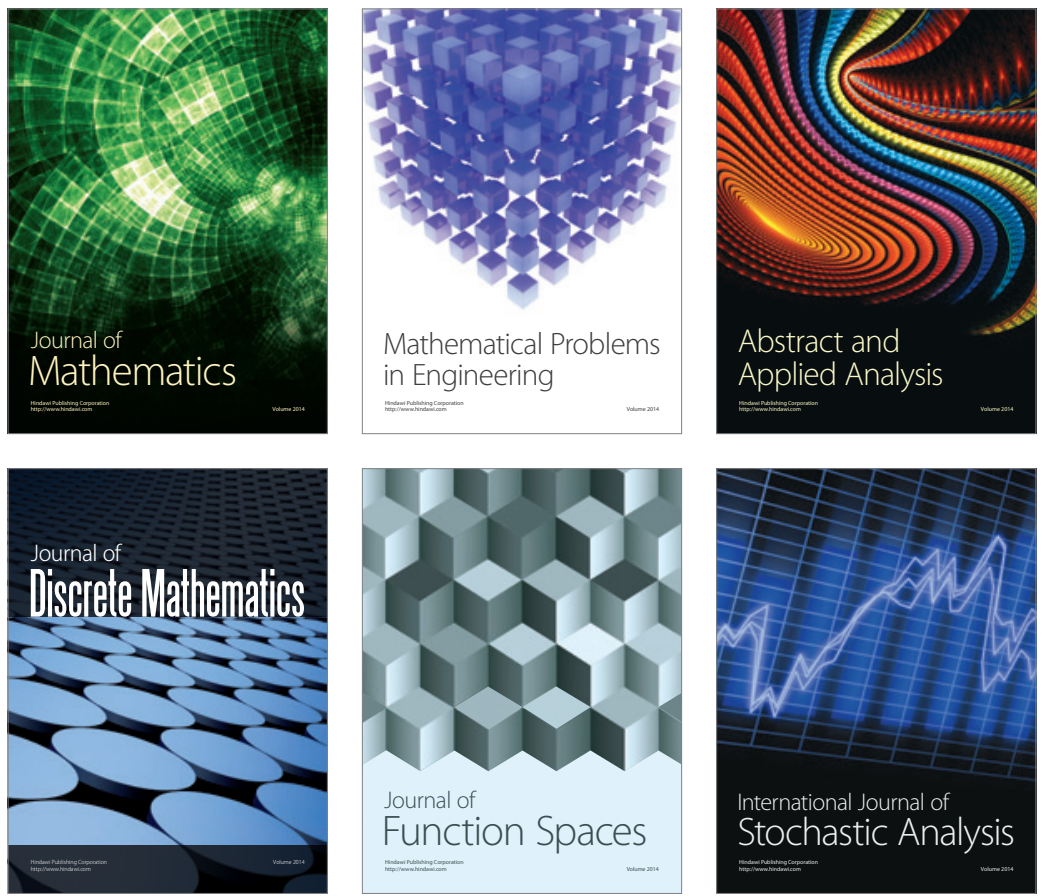

Journal of

Function Spaces

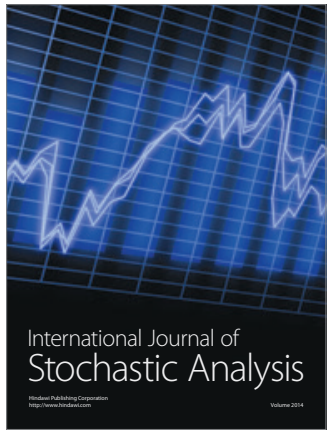

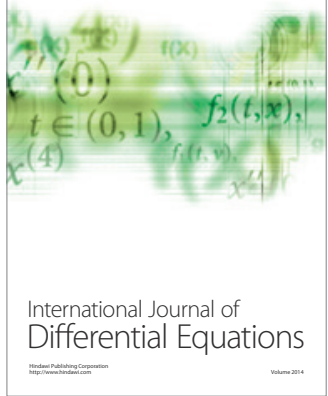
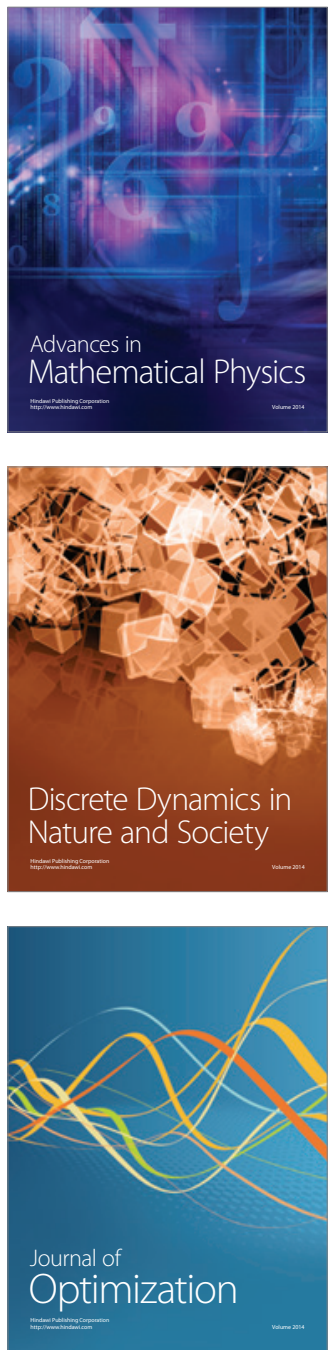